\title{
The Digital Landscape: The Hawaiian Newspapers and War Records and Trust Territory Image Repository of the University of Hawaii
}

\author{
iy bines Cartwitglit:

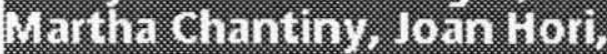 \\ and Rarer iseacess?
}

This paper discusses the nature of three image collections - Hawaiian language newspapers, Hawaii War Records Depository (HWRD) and Trust Territory of the Pacific Islands Photographs - as well as future plans and desires for these digital collections, funded as an IMLS project.

\section{Contents}

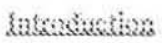

Diknsesioni

conciown

\section{Introduction}

The University of Hawaii at Manoa (UHM) Library has traditionally had strong ties and a responsibility for serving information needs in the Pacific Islands region. The Hawaiian Newspapers, War Records, and Trust Territory Image Repository Project broadens the range of Library services and provides library and research institutions in the Pacific region with opportunities to interact directly with sources which were formerly beyond their reach. The IMLS-funded project will provide a mechanism to explore the utility of digital surrogates for the local, national, and international research community. This Project hopes to demonstrate that wider access to these materials will significantly strengthen Hawaiian and Pacific historical scholarship. These three collections represent significant historical resources of interest nationally and internationally: These three collections will create a foundation to begin building a true digital library of Hawaiian and Pacific resources.

\section{Trust Territory of the Pacific Islands Photo Collection}

From 1947 to 1994 the United States was the administering authority under the United Nations for the Trust Territory of the Pacific Islands (TTP1), an area that originally included the Micronesian archipelagoes of the Marshalls, Carolines and Marianas. Today the Federated States of Micronesia (Pohnpei, Kosrae, Chuuk and Yap), the Republic of the Marshall Islands, and the Republic of Palau have autonomous governments in free association with the U.S., and the Northern Marianas has a commonwealth relationship with the U.S.

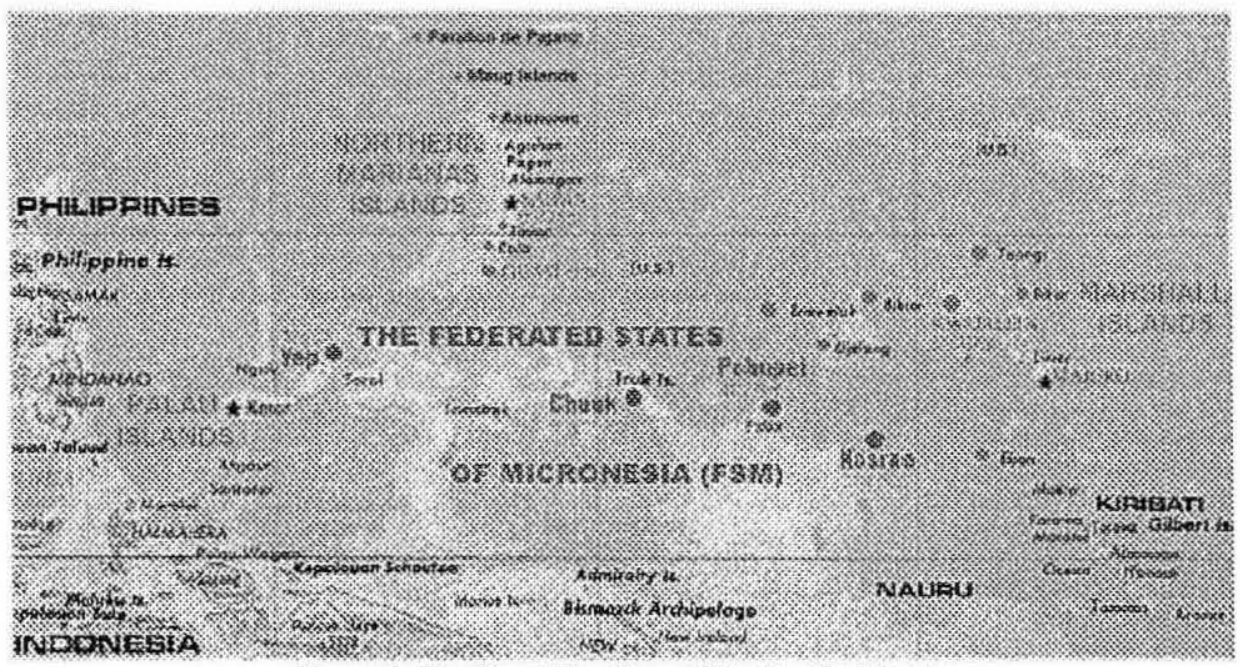

Figure 1: The Trust Territory of the Pacific Islands. 
When the Trusteeship began to scale down operations in the 1980 s, a collaborative effort between the University of Hawaii at Manoa and the Trust Territory Government was formed to preserve the records of the U.S. Administration's programs in education, health, political, and economic development. A team on Saipan indexed and microfilmed documents, and a complete set of the film and the final index was deposited with each island government and with the UHM Library. In addition, UHM Library received the Trust Territory Archives Photo Collection of some 50,000 photographs and over 2,000 slides that illustrate the history of the American period in Micronesia from 1947 to 1988.

In 1991 the UHM Library received a Higher Education Act Title Il-C federal grant to select significant items from the Trust Territory Photo Collection, add descriptive information to the existing bibliographic records (in the Trust Territory Archives Database, a subsystem of the Library's automated system), scan photographs and slides to produce digital image files, and link the digitized images to the online catalog records. Over 6,600 photographs representing the highlights of the collection were selected by the Pacific Curator after an inventory of all holdings was conducted. The digitized images record island cultures (traditional buildings, dances, feasts, costume, art, canoes), political events (opening of the Congress of Micronesia, inauguration of the independent governments), and document the areas of U.S. Trusteeship activity in health, education, economics, and other fields.

The images (in TIFF format) created via the Title II-C project were only accessible in the Reading Room of the Special Collections Department at UHM Library from two dedicated workstations connected to a standalone optical jukebox located in the Library's computer room. The conversion of the TIFF images and transfer to a server dedicated to image file access is now underway. The LMLS project will also create CD-ROM(s) of the Web pages and image for distribution to Pacific Island Libraries and research facilities. Web access and CD-ROM distribution will make this resource available internationally in as many formats as possible to accommodate a variety of technical levels.

\section{Hawaiian Language Newspapers on microfilm}

Hawaiian language newspapers are primary historical materials which document a unique period in Hawaiian and American history: Among the early papers were those begun by American missionaries to Hawaii. The newspapers are considered a standard for written Hawaiian which was nearly extinct a few years ago, but has reemerged as a language of daily use and scholarship. They include stories and chants, photographs and advertisements, political notices, and letters to the editor.

These newspapers are currently stored on microfilm, which was produced from newspapers that had deteriorated through the years. The original microfilming project was a cooperative endeavor of libraries, archival collections, and museums in Hawaii. Through subsequent heavy use by students and scholars of the Hawaiian language, some of the microfilm copies available at the UHM Library have deteriorated and/or disappeared. At the time of microfilming of these newspapers, copy masters were not made, and the existing archival masters must therefore be used for reduplication when replacement reels are needed. Each reduplication from an archival master reel causes a bit of deterioration and places it at risk. The emerging technology of digital scanning furnishes an opportunity to provide access to these important newspaper resources without destroying the resource itself.

In Spring 1997 three libraries of the University of Hawaii system received a small grant from the campus Student Equity, Excellence, and Diversity (SEED) program for a pilot project to digitize selected Hawaiian language newspaper articles currently stored on microfilm, enhance them optically, and mount them on the World Wide Web. In the four months of phase 1, over 3,800 images were scanned from microfilm. In addition, twenty-two series and articles selected from Hawaiian language newspapers were printed from the microfilm and prepared for scanning. In Spring 1998 the UHM and UH Hilo Libraries received a second Diversity and Equity grant to fund the salary of a student assistant to continue processing the scanned images. The IMLS-funded Project has added eight more titles to the list of digitally scanned newspapers, and scanning of an additional title has been funded by a small grant from the Hawaii Committee for the Humanities.

\section{Hawaii War Records Depository Photographs}

The Hawaii War Records Depository (HWRD) was created in 1943 by the first territorial legislature to meet after the Army declared martial law in the Hawaiian islands on December 7, 1941. With great foresight, the legislature specified the collection was to document the effects of the War upon Hawaii and its populace. It appropriated funds for the collection of materials to be stored at the University of Hawaii and for personnel to process, preserve and catalog the materials. 


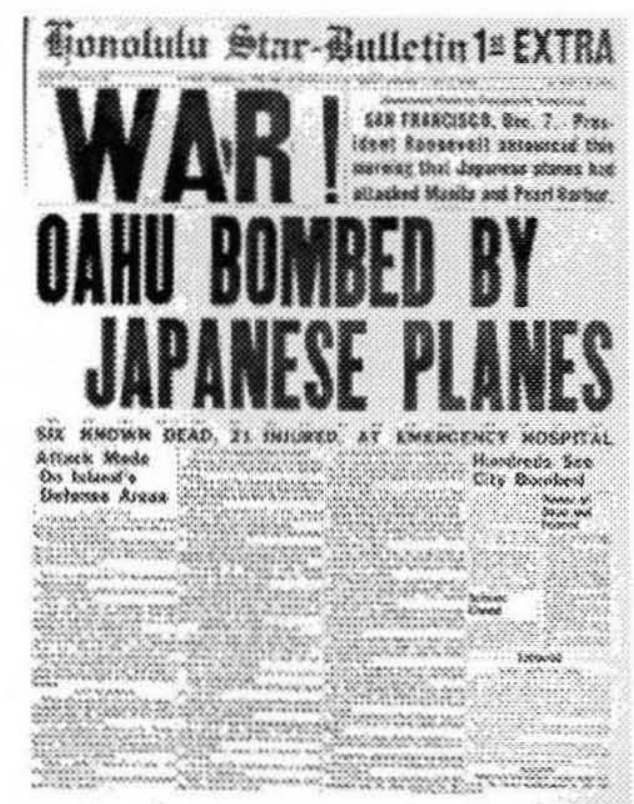

Figure 2: Page One of the Honolulu Star-Bulletin from the Hawaii War Records Depository.

HWRD holds approximately 1,000 newspaper photographs clearly identified as being from the Honolulu Star Bulletin and 325 photographs clearly identified as being from the Honolulu Advertiser, representing primary material from the two English-language Honolulu newspapers. Because the newspapers have lost most of their old photographs, these prints frequently are the only copies extant from the time of the War. In this project, we will create descriptions for the photographs scanned and provide the capacity for patrons to search descriptions using personal names, corporate or organizational names, subjects, or dates. The Honolulu Star Bulletin and Honolulu Advertiser have given permission to post digital images of photographs created by the photographic staff of the Star Bulletin and the Advertiser. A copyright statement appears on each photo, and the investigation of the use of watermarking technology is underway.

\section{Discussion}

\section{Hawaiian Language Newspapers}

From 1834 to 1948 approximately 80 Hawaiian language newspapers were published in Hawaii. Presenting a Hawaiian view of historical events in Hawaii and the world, and a Hawaiian perspective on the native culture, these newspapers are a unique and important source of information.

Collections of the Hawaiian language newspapers were scattered in libraries and archives throughout the state of Hawaii. In the mid-1980's the Hawaii Newspaper Project to preserve ethnic newspapers in Hawaii received a grant from the National Endowment for the Humanities to list all known extant newspapers published in Hawaii since 1834 and to microfilm these Hawaiian and other ethnic newspapers. This project served to provide increased access to deteriorating newspapers in the languages of the native and immigrant peoples of Hawaii [1]. 


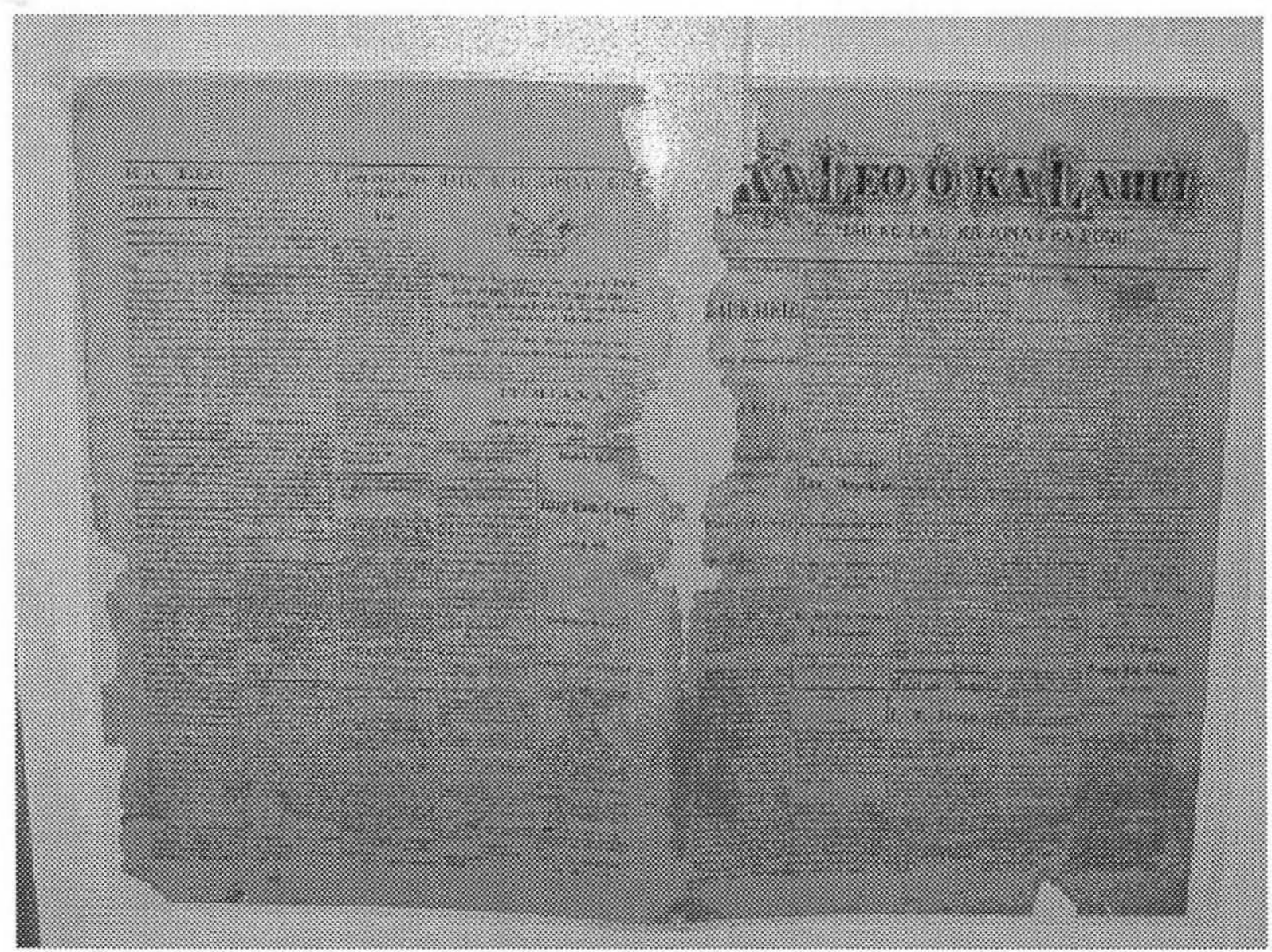

Figure 3: Ka Leo o ka Lahui, a 19th century Hawaiian language newspaper.

The first Hawaiian language newspaper, Ka Lama (The Torch), appeared in February 1834, only 14 years after the arrival of the American Protestant missionaries sent by the American Board of Commissioners for Foreign Missions. Immediately after their arrival in 1820, the missionaries studied the Hawaiian language, analyzed it, and in 1826 established its orthography. Ka Lama and a second newspaper, Ke Kumu (The Teacher), also published in 1834, were not the first publications in the Hawaiian language. A spelling book had been published in 1822 [2]. These two newspapers were the first of numerous Protestant mission-sponsored newspapers. In subsequent decades newspapers in the Hawaiian language were published by Roman Catholic missionaries, and the Reorganized Church of Jesus Christ of the Latter Day Saints. Filled with educational material, the newspapers were intended to contribute to the religious and educational efforts of the missionaries.

In 1861 appeared the first of the Hawaiian language newspapers edited by native Hawaiians, Ka Hoku o ka Pakipika (Star of the Pacific, published 1861-1863) [3]. With Ka Hoku o ka Pakipika began a period of Hawaiian nationalism in the language newspapers. Others in this category are Ke Au Okoa (The New Era, published 1865-1873), and Ka Manawa, (Time ) which was the first daily in Hawaiian and appeared in 1870. Ka Makaainana, (The Citizen, or Commoner, published 1887-1899), and Ka Leo o ka Lahui (The Voice of the Nation, 1889-1896) continued the support of Hawaiian independence [3]. These are all represented in the Project.

The newspapers selected for the Web demonstrate a variety of sizes and condition as well as political and religious viewpoints and historical periods. They are Ka Lama (1834), Ka Hoku o ka Pakipika (1861-63), Ke Au Okoa (1865-73; only 1865 issues have been digitized), Ka Manawa (1870), Ka Makaainana (1887-99), Ka Leo o ka Lahui (1889-1896), Ka Lei Momi (1893), Ka Lei Momi e Mau Kou Olino Ana (1893), Ka Loea Kalaiaina (1897-1900), Ka Lanakila (1909), Ke Au Hou (1910-12), Hawaii Holomua (1912).

The current Project sponsored by the Institute of Museum and Library Services (IMLS) National Leadership Grant is the largest in a series of grant-supported efforts to digitize Hawaiian language newspapers for the World Wide Web. Initially a cooperative start-up endeavor of several campuses of the University of Hawaii, the project began with seed money from the University of Hawaii President's Diversity and Equity Grant in 1997. Since then, funding has been received to digitize additional titles and to purchase Web-accessible computers for University programs for student communities with large numbers of Hawaiian students on islands where the microfilm is not available.

Students at the University of Hawaii at Manoa may work toward a Bachelor of Arts degree in the Hawaiian language. They may also major in Hawaiian Studies, a program that also offers courses taught in the Hawaiian language. Newspapers are used in second year language classes. More advanced students compare variations of famous stories, study chants and genealogies published in the papers, and look at ads and personal notices. They read the contemporary accounts of events such as the overthrow of the Hawaiian monarchy; they follow letters to the editors and editorials. Language teachers search for grammatical patterns and examine the ways in which the language has changed.

Some representative comments from among the many that have been submitted via the survey form on the Web page illustrate the use and 
importance of the resource - and the resurgence of the Hawaiian language as a living language:

University student@maui.net

No ko'u a'o 'ana a nui ko'u makemake e heluhelu e pili ana o ko kakou kupuna a a'o ke kumu no keia ola. Mahalo no ka wehe 'ana o keia alahele e a'o.

[For my learning and my great desire to read about our ancestors and the reason of this life. Thank you for the opening of this method of learning] (translation supplied by Martha Chantiny)

University language student @leoki.uhh.Hawaii.edu

Ua makemake wale wau e mahalo aku $i$ ka mea nana e auamo nei $i$ keia nui hana no ka pono o ka nui o kakou poe olelo Hawaii. He pono no keia, a he pomaikai maoli no. Mahalo.

[I wanted to thank the person(s) carrying on this important work for the benefit of most of us. It is necessary, and truly fortunate (blessed). Mahalo.] (translation supplied by Martha Chantiny)

\section{Researcher@gte.net}

I am a Hawaiian Immersion teacher always looking for sources of Hawaiian information, vocabulary, and examples. I never have the time to go to U.H. to use the microfilm. I would just like to extend a great big mahalo to you and all the work that you are doing to get this very important and useful information and stories out and more accessible. As a Native Hawaiian, a Hawaiian language student, a teacher 1 greatly appreciate your hard work. Thank you, again. You can be sure that 1 will be utilizing this site a lot.

A recently received Hawaii Committee for the Humanities grant will support the digitization of the Hawaiian language newspaper with the longest publication history, Ka Nupepa Kuokoa (The Independent, 1861-1927). It was published with missionary support and while demonstrating a non-native stance, it had a long history of publishing information about Hawaiian traditions and cultures and continues to be a well-used source of information. Ka Nupepa Kuokoa has been an often-requested title by users of the digitized newspapers.

Hawaiian is a language that has been revived from near extinction by dedicated teachers and students who fought to establish elementary and secondary immersion schools [?]. The newspapers are serving as supplementary language texts, and an aural component is envisioned that would enhance the experience of the language learner, so that both reading and listening could take place at the Hawaiian language newspaper Web site.

The newspapers on the Web are image files, which are not searchable. Conversion to text would enable the searching of names, words, places, and language patterns. An attempt to use an optical character recognition program failed due to the old and different fonts used in the printing of the newspapers. Adding voice and searchable texts would enhance the site and make a well-used research and instructional tool even more useful to the speakers and students of the Hawaiian language. These are enhancements that we hope to be able to provide at some point in the future.

\section{Newspaper Photographs in the Hawaii War Records Depository}

When the opportunity of scanning some of the photographs in the Hawaii War Records Depository onto a Web site came through a potential grant from the Institute of Museum and Library Services, we were excited about the possibilities. The Hawaii War Records Depository (HWRD) was created by the Territorial Legislature of Hawaii during the first session it was allowed to meet after the bombing of Pearl Harbor. The purpose of HWRD was to document the effects of the War upon peoples of Hawaii. Before long people began sending in photographs to the staff of HWRD. As a result the collections soon had a significant number of photographic prints. After United States military photographs, the two most significant contributors were the two daily newspapers in Honolulu, the Honolulu Star Bulletin and the Honolulu Advertiser. These photographs, contrary to the military photographs, emphasize the lives of citizens of Hawaii. The holdings of HWRD amount to approximately 3,000 photographic images, 71 reels of microfilm, 40 file drawers of manuscript materials, plus ephemera.

Years later, in the early 1960 s, a joint operating agreement between the two Honolulu newspapers resulted in their sharing facilities. The Honolulu Star Bulletin moved into the Advertiser building. To make room for the sharing of space, both newspapers discarded their old photographs. As a result, the newspaper images in HWRD of war time Hawaii are frequently the only surviving copies of those photographs. Making them available via the Internet would bring them to a much wider audience within this state whose citizens are scattered among seven islands as well as to the nation and world at large. So, when faced with this opportunity, selecting the newspaper photographs within HWRD as our target became almost automatic.

The photographic images in HWRD have always been highly used. During a typical year, we receive requests for access to and copies of photographs from school students to use in History Fair presentations, from college students preparing papers, and from scholars preparing monographs for publication. During special years, such as 1991, the fiftieth anniversary of the attack on Pearl Harbor, the patron use of HWRD reached a phenomenal level with television, radio, and print news media from Australia, Japan, Canada, and the United States Mainland joining all the other users. That year also showed an heavy increase in scholars using HWRD materials as they prepared to publish works during the anniversary year. Based upon the past, our expectations for the use of the scanned newspaper photographs from HWRD will primarily be students with some scholars.

Because the only cataloging done for the vast majority of material in HWRD occurred in the late 1940s as the items came to HWRD and did not meet library standards even for the 1940 s, the scanning project automatically required us to create metadata records of each item scanned to accompany the images. The IMLS grant included funding for participation in a metadata workshop sponsored by OCLC in Dublin, Ohio. Along with other participants in the workshop, we created a template of fields from the Dublin Core for metadata on each item. We chose to use the title field twice, unqualified to handle the description of the photographic print as written either on the reverse of the print or attached to it, and the "alternative" title field to cover the caption accompanying published images in the newspaper. Likewise, 
we chose four potential date fields for each photograph. Most images will only need two of them. Occasionally, however, a photograph will date from one day, depicting the events of another day, be published in the newspaper on a third day, and be scanned on a fourth day. Since researchers may need these dates distinguished, we decided to have the option for all four dates.

The Dublin Core offers several options on subject fields as well. We included in the template subject field qualified as Library of Congress Subject Heading, another qualified as "keyword," another for corporate names and a fourth for personal names. Since many of our users will be searching subjects using common vocabulary, rather than the officially recognized LCSH, we knew that we needed the keyword option. Thus searches for Varsity Victory Volunteers and Americans of Japanese Ancestry as well as the well-known acronyms VVV and AJA will retrieve Japanese American soldiers who fought during World War II. Likewise, using the common term for an official organization where the two differ significantly will allow users to find appropriate images because of our use of the "keyword" attribute in the subject field.

We hope in the future to expand our scanning of materials to include some of the unique items within the manuscript collections of HWRD and related collections which document lives of citizens of Hawaii during and following World War II.

\section{Trust Territory of the Pacific Archives}

In the past nine years six books have been published that make extensive use of Trust Territory (TT) Archives photos held at the UH Library's Pacific Collection.

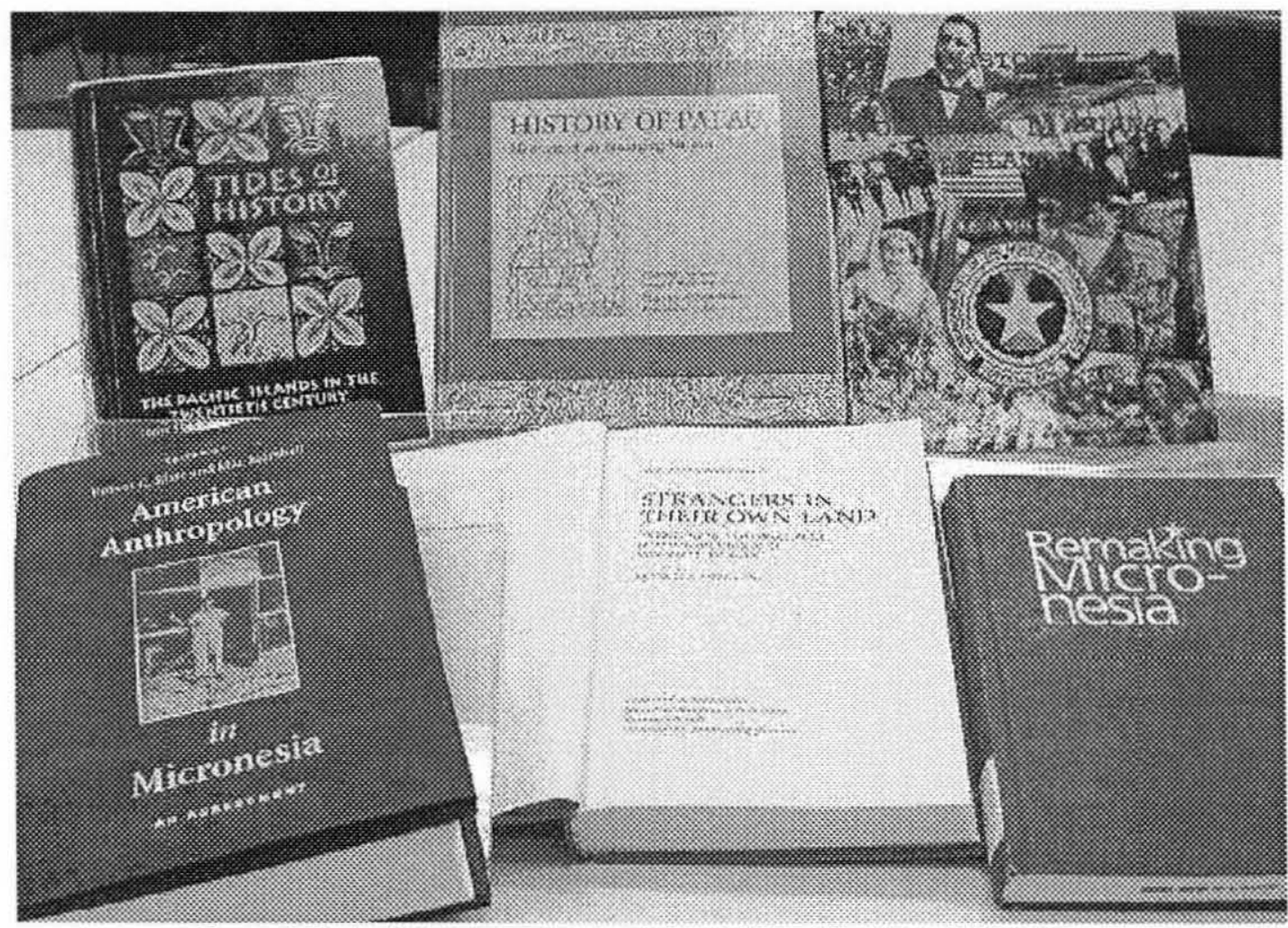

Figure 4: Books that have made extensive use of Trust Territory (TT) Archives.

Two new projects underway will also use photographs from our archives. The Pacific Curator works closely with each of the authors in their search for appropriate illustrations. Requests have often centered on particular individuals (such as President Lazarus Salii of Palau), examples of social change (USDA food on the dock), cultural activities (pounding sakau [kava]), or political events (inauguration of the first president of the Northern Marianas).

Researchers, historians, and anthropologists have used the online (text) index to the Trust Territory Archives to locate material. Once the author finds an appropriate photo, the image is called up and displayed at the workstation terminal. Until now the images have only been available at $\mathrm{UH}$, therefore the authors were required to travel to the UH Library to view the images even at the preliminary manuscript planning stages. On site, the advantage of providing the digital surrogate images meant that time could be saved making preliminary decisions about illustrations. A researcher then either can view the original which is retrieved from the vault, or can immediately complete a request form to create a copy of the photo.

When the TT Archives images become available on the Web, searching will be fully functional from any location. Thus, Fr. Hezel of the Micronesian Seminar in Pohnpei, who used our photos in his history of Micronesia and who visited the Library earlier this year to search for photos for his new book on social change in Micronesia, will be able to do his searching "from home," and simply e-mail or send a list of photos for duplication.

Even more importantly, researchers and teachers will have access to the photos for class use. As an example, Joachim Peter of Chuuk teaches cultural studies for the College of Micronesia. He is a graduate of UH with master's degrees in Pacific Studies and History: Mr. Peter is trying to develop in students an interest in their own past, their history and their culture. Photos from Chuuk (or Truk as it was 
called in the past) in our database will give Mr. Peter's students, who have Web access, the ability to see former political leaders, traditional chiefs, cultural ceremonies, buildings, canoes, and ordinary folk - among whom they may see relatives - in school, at work, and in the hospital. Web access will also mean that Mr. Peter and his students can make printed copies of our photos for use in class projects, exhibits, and research papers. This scenario will be repeated throughout the countries of Micronesia.

We are also hoping that Web access will give us a means of obtaining feedback from users. There are many unidentified people and places in the photos that we have scanned. We would like to ask users to write or e-mail us with information that will allow us to expand our cataloging of these photographs. We envision an exchange of information that will make the database even more complete and helpful to users.

\section{Project Production and Technical Details}

The project uses a Minolta Microdax microfilm scanner and an Agfa Duoscan flatbed scanner as well as an HP. scanjet for "quick and dirty" work: Software used includes the proprietary Mdax application for the microfilm scanning and scanning software which came bundled with the two flatbeds, Paintshop Pro for graphic file editing, HomeSite for HTML file creation and editing, Adobe Capture for PDF conversion. Our overall emphasis is on using the lowest cost effective solution for our needs.

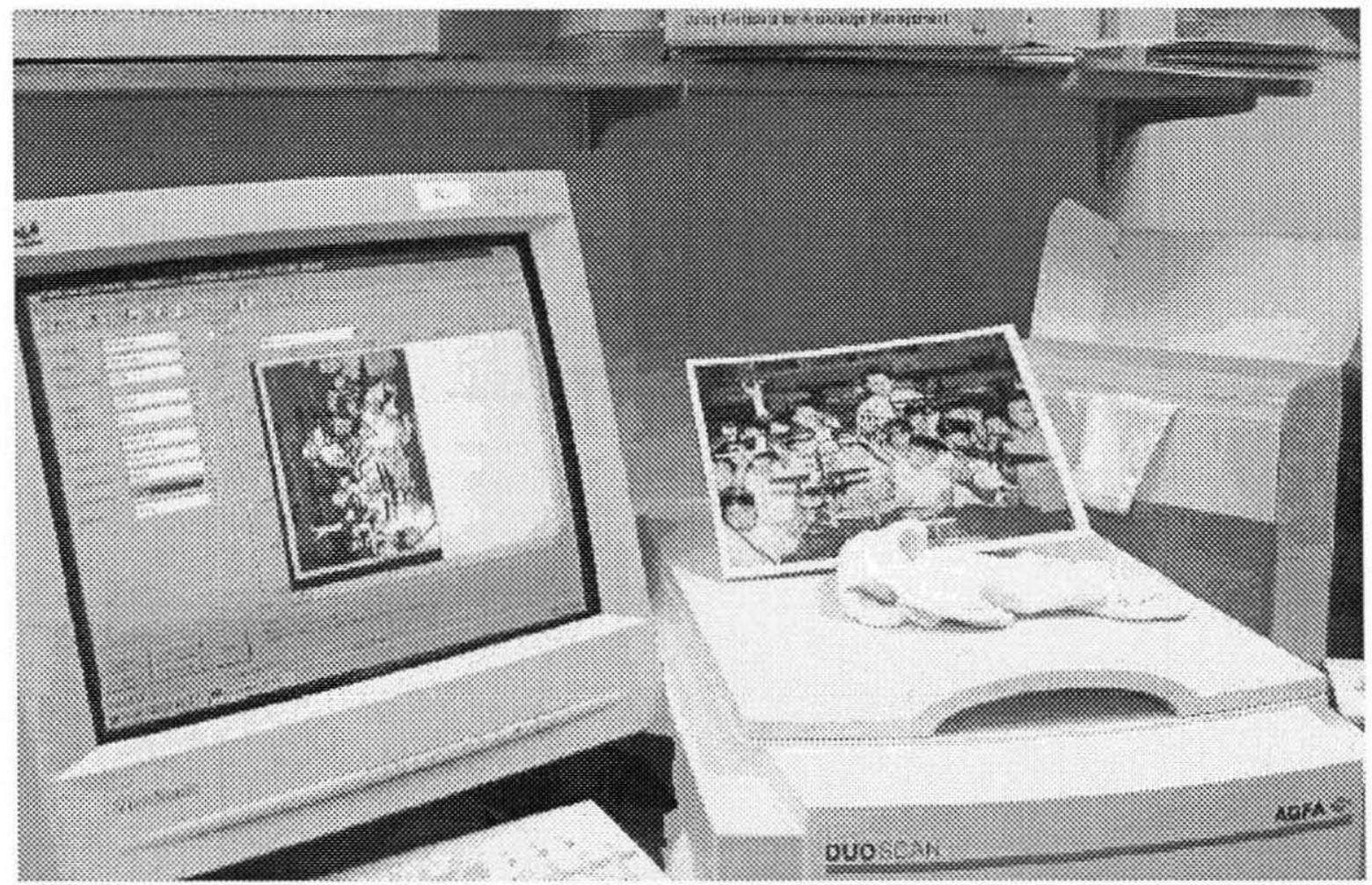

Figure 5: Scanning equipment used in processing images for the Project.

We have experimented with using OCR and "cleanup" software - Cuneiform and ScanFix, respectively; for post processing of the images of the Hawaiian language newspapers. The products work fairly well, and as advertised, but we have found that the vagaries of the 19th century fonts - combined with blots, tears, wrinkles, stains, and other image distorting features that were captured in the microfilm image because of the poor quality of the original newspapers being filmed - do not allow us to effectively use either program.

We have found that our user population, while not stunningly large, is diverse and global as shown by our server statistics for the period June-December 1999:

Average successful requests per day: 792;

Distinct hosts served: 1,661

Connections from:

83.13\%: .edu (USA Educational);

8.40\%: .com (Commercial) .net (Network) .org (Organizations) .mil (US Military) and .gov (US Government)

Countries/Domains: .uk (United Kingdom) .jp (Japan) .be (Belgium) .nl (Netherlands) .mx (Mexico) .br (Brazil) fr (France) .ca (Canada) .nz (New Zealand) .sg (Singapore) .fm (Micronesia) .in (India) .es (Spain).gr (Greece) .no (Norway) .ck (Cook Islands) .il (Israel) .hu (Hungary) .tw (Taiwan) .ro (Romania) .my (Malaysia) .sk (Slovak Republic) .yu (Yugoslavia) .de (Germany) .dk (Denmark) .pf (Polynesia (French) .au (Australia)

The project has funding for two 20-hour student assistant positions, therefore we have relied heavily on unpaid Library School program interns to augment our "shoestring operation". This is a very positive, "win-win" situation that has to date provided nine MLIS graduate 
students with hands-on experience with the practice and theory relating to the creation of digital collections. Student evaluations of the internship experience have reported:

"This ... internship ... was an excellent way to obtain work experience in a new area of library and information science ... it is exciting to know that 1 have experience in the Dublin Core, digitization of images, and metadata. 1 strongly recommend this internship ..."

"I appreciated [learning] my way around the world of PCs and having the opportunity to use excellent equipment. I appreciated being allowed ... to experiment ..."

"Theory is fine, but there is nothing like doing the work. ... Web publishing is certainly a dynamic, interactive and immediate process. This was an excellent educational experience."

"I benefited a lot from this internship that provided me with a good chance to apply what 1 learn from the classroom to the practice. With the development of information technologies, libraries will depend on computers ... Therefore ... mastering digitization skills will become basic requirements to MLIS graduates ... 1 think this internship prepared me in advance for the future."

"This internship has been both challenging and rewarding ... Many thanks for giving me enough options to make the work pleasant while learning new things."

\section{Conclusion}

We are so busy just DOLNG that it is difficult to find the time to reflect upon the larger issues that creation of a digital image collection raises. A few truisms from the ground that can safely be called conclusions are:

- It STILL always takes longer than you thought it would

- OCR of 19 th century non-English fonts is still more trouble than it is worth

- No matter what the scale of the project, it continues to be difficult to balance production speed with quality

- Questions about presentation/arrangement of image information on the Web never have easy or permanent answers

- Last but not least, providing expanded access to resources that are of vital importance to our users is what makes it rewarding and worthwhile.

(x)

\section{About the Authors}

James Cartwright is the University Archivist at the University of Hawaii at Manoa. He has a BA and MA in English literature from BYU, an MS in History from the University of Utah, an MLIS from the University of California, Berkeley. He is a member of the Society of American Archivists (SAA) and has been on the steering committee of the Congressional Papers Roundtable of the SAA. He is a member of the Association of Hawaii Archivists (AHA), has served on its Board and is currently the editor of the AHA newsletter.

Martha Chantiny is the Head of the Desktop Network Services unit within the Information Technology Division at the Hamilton Library, University of Hawaii at Manoa. She has a BA in Anthropology from the University of Hawaii at Hilo and an MLIS from University of Hawaii at Manoa. She has been involved in a wide range of electronic/digital information initiatives, services, and projects as well as implementation of online library systems at the four-year and Community College campuses of the University of Hawaii system. She is a member of the American Society for Information Science.

Joan Hori is the Curator of the Hawaiian Collection in the Special Collections department at the University of Hawaii at Manoa Library. She has a BA and a MA in Asian Studies, an MLS, and a certificate in Hawaiian language from the University of Hawaii. She is a member of the Hawaii Library Association, Association of Hawaii Archivists, and Hawaiian Historical Society.

Karen Peacock is the Pacific Curator in the Special Collections Department at the Hamilton Library, University of Hawaii at Manoa. She has a BA in Sociology from Earlham College, an MA in Pacific Studies, an MLS and a PhD in History, all from the University of Hawaii at Manoa. She is a member of the Hawaii Library Association, Pacific Islands Archives and Libraries Association, and Pacific History Association. She serves as a faculty member of the Center For Pacific Islands Studies and is the editor of the resources section of The Contemporary Pacific: A Journal of Island Affairs.

\section{Notes}

1. Hawaii Newspaper Project, 1987. Hawaii Newspapers: A Union List. Honolulu: s.n.

2. For a historical description of the Hawaiian language, see Albert J. Schütz, 1994. The Voice of Eden: A History of Hawaiian Language Studies. Honolulu: University of Hawaii Press.

3. Helen Chapin provides an essay on the various Hawaiian language newspapers in "Newspapers of Hawaii 1834 to 1903: from 'He Liona' to the Pacific Cable," Hawaiian Journal of History, volume 18 (1984): pp. 47-86. 
4. Esther Mookini's The Hawaiian Newspaper (Honolulu: Topgallant Pub. Co., 1974) details editors, dates of publication, political/religious stance, etc.

5. See Schütz for a description of nineteenth-century policies that resulted in decreasing numbers of native speakers and the revival of the language since the 1970 s.

\section{Bibliography}

Forthcoming works that use Trust Territory Archives photos as illustrations:

There are two works underway now that will use TTP photos:

- Francis X. Hezel, S.J. Social Change in Micronesia, 1950-2000.

- Samuel McPhetres. History of the Marshall Islands, forthcoming from Dept. of Education, Republic of the Marshall Islands.

Published works that use Trust Territory Archives photos as illustrations:

- Anthropology in Micronesia, edited by Robert C. Kiste and Mac Marshall. Honolulu: UH Press, 1998.

- Don A. Farrell. History of the Northern Mariana Islands. Saipan: Public School System, 1991. 701 p.

- David Hanlon. Remaking Micronesia: Discourses Over Development and Other Ethnographic Considerations in a Pacific Territory, 1944-1982. Honolulu: UH Press, 1998.

- Francis X. Hezel. Strangers in Their Own Land: A Century of Colonial Rule in the Caroline and Marshall Islands. Honolulu: Center for Pacific Islands Studies, UH and UH Press, 1995.

\section{Videos That Use Trust Territory Archives Photos}

- Lieweila: A Micronesian Story. Producers: Cinta Matagolai Kaipat and Dr. Beret E. Strong. Boulder, Colo. 57 min. $30 \mathrm{sec}$. Color. The video cover uses a TTA photo of a Carolinian voyaging canoe and crew.

\section{Selected Books Using Sources in HWRD}

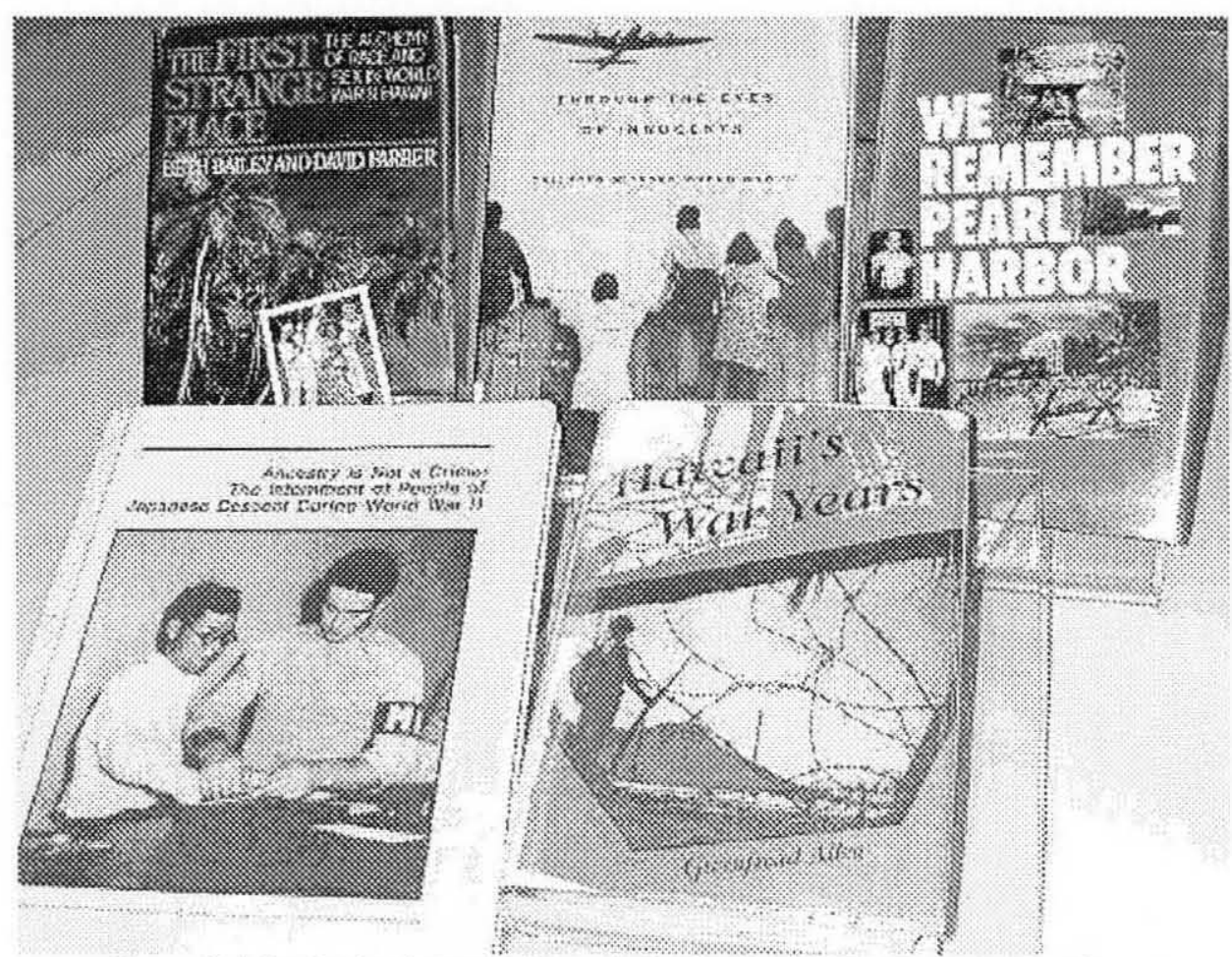

Figure 6: A few books that use information in the Hawaii War Records Depository.

- Gwenfread Allen. Hawaii's War Years. Honolulu: University of Hawaii Press, 1950. This work was commissioned by the Territorial Legislature to be written from materials comprising the Hawaii War Records Depository:

- Beth Bailey and David Farber. The First Strange Place: Race and Sex in World War Il Hawaii. New York: Free Press, 1992; Baltimore: Johns Hopkins University Press, 1994.

- Thurston Clarke. Pearl Harbor Ghosts: A Journey to Hawaii Then and Now. New York: William Morrow, 1991.

- Lawrence Reginald Rodriggs. We Remember Pearl Harbor: Honolulu Civilians Recall the War Years, 1941-1945. Newark, Calif: Communications Concepts, 1991.

- Michael Slackman. Target, Pearl Harbor. Honolulu: University of Hawaii Press; Arizona Memorial Museum Association, 1990.

- Lilian Y. Yamasaki, Eileen H. Tamura, and Linda K. Menton. Ancestry is Not a Crime: The Internment of People of Japanese Descent During 
13

World War II.' Honolulu: Office of Instructional Services, Dept. of Education, State of Hawaii, 1994.

\section{Editorial history}

Paper received 1 May 2000; accepted 10 May 2000.

The Digital Landscape: Hawaiian Newspapers, War Records; and Trust Territory Image Repository of the University of Hawaii by James Cartwright, Martha Chantiny, Joan Hori, and Karen Peacock

First Monday, volume 5, number 6 (June 2000), 